\title{
Associations between Age of Gilts at First Mating and Lifetime Performance or Culling Risk in Commercial Herds
}

\author{
Hikari SAITO $^{1)}$, Yosuke SASAKI ${ }^{1)}$ and Yuzo KOKETSU ${ }^{1) *}$ \\ ${ }^{1)}$ School of Agriculture, Meiji University, Kawasaki, Kanagawa 214-8571, Japan
}

(Received 27 January 2010/Accepted 30 November 2010/Published online in J-STAGE 14 December 2010)

\begin{abstract}
Age of gilts at first mating (AFM) is a factor associated with reproductive performance of female pigs. The objectives of the present study were to compare AFM and reproductive performance across parity between three herd groups based on a productivity measurement and to determine lifetime performance by AFM and the herd groups. The female data included 38,212 mated gilts entered between 2001 and 2003, and the herd data included mean measurements from 2001 to 2006 in 101 herds. The average female inventory of the 101 herds was 370.2 females. Females were categorized into five groups: AFM 188-208, 209-229, 230-250, 251-271 or 272365 days. Three herd groups were formed on the basis of the upper and lower 25 th percentiles of pigs weaned per mated female over six years: high-, intermediate- and low-performing herds. Multilevel mixed-effects models were performed to analyze comparisons. The AFMs ( \pm SEM) in the high-, intermediate- and low-performing herds were $239.5 \pm 0.22,247.4 \pm 0.21$ and $256.7 \pm 0.35$ days, respectively. As the AFM increased from 209-229 to 272-365 days, annualized lifetime pigs born alive (PBA) decreased from 18.2 to 15.3 pigs, and the number of parities at removal decreased from 4.8 to $4.1(P<0.05)$. In parity 1, females with an AFM of 209-229 days had fewer PBA, but had a lower culling risk and shorter weaning-to-first mating interval than those with an AFM of 251-271 days $(P<0.05)$. In conclusion, we recommend management practices such as boar exposure to hasten puberty in gilts and decrease AFM.
\end{abstract} KEY WORDS: age at first mating, culling risk, gilt, herd management, litter size.

J. Vet. Med. Sci. 73(5): 555-559, 2011

Lifetime performance and longevity are critical for producers managing commercial herds [5]. Increased lifetime performance and longevity in female pigs (females) reduce costs of replacement gilts and improve herd performance [12] and profitability. Age of gilts at first mating (AFM) has been suggested to be a key factor determining lifetime performance and longevity $[12,13]$. Higher AFM is associated with higher numbers of pigs born alive (PBA) [1], but with a lower farrowing percentage [7] and longer weaning-toestrus interval in low parity [16]. Furthermore, a high age of gilts at first conception has a significant negative effect on longevity and increased hazard of culling [13]. However, the relationships between AFM and by-parity reproductive performance such things as farrowing percentage, weaningto-first mating interval (WMI) and culling risk have not been fully elucidated.

Annual measurements of herd performance for females in high-performing herds based on the number of pigs weaned per mated females per year (PWMFY) have been reported to provide productivity and performance benchmarks for the swine industry $[5,15]$. However, the relationship between AFM and herd groups based on PWMFY has not yet been examined. Additionally, there have not yet been any reports of the relationships between AFM and herd groups in terms of lifetime performance or longevity. Therefore, the objectives of the present study were to compare AFM and reproductive performance by parity between herd productivity groups and to determine culling risk and lifetime perfor-

\footnotetext{
* Correspondence to: Koketsu, Y., School of Agriculture, Meiji University, 1-1-1 Higashi-mita, Tama-ku, Kawasaki, Kanagawa 214-8571, Japan.

e-mail: koket001@isc.meiji.ac.jp
}

mance according to AFM and herd groups.

\section{MATERIALS AND METHODS}

Herds: Producers (approximately 130 herds) in Japan using a recording software (PigCHAMP ${ }^{\circledR}$ Inc., Ames, IA, U.S.A.) were requested to mail their data files to Meiji University when they purchased the software or renewed their yearly maintenance contract. In February 2007, Japan had 6,560 breeding herds and 915,000 females [9]. Therefore the data in the present study included approximately $2.0 \%$ of all Japanese herds and approximately $5 \%$ of female inventories in Japan in 2007. By 31 August 2007, data files had been received from 123 herds. Records of birth dates in each herd were checked for a histogram of the day within the month in the birth dates of the gilts. Of the 123 herds, 7 were grow-to-finish operations, 12 had no records of AFM, 1 had inaccurate birth dates and 2 had produced only purebred pigs, so these 22 herds were excluded from the study. Therefore, the data for 101 herds were used for further analysis. The mean herd measurements over the 6 years between 2001 and 2006 were also extracted from the records for each herd. The females in the study herds were mainly crossbreds between Landrace and Large White or gilt replacements purchased from international breeding companies. The average female inventory in the 101 herds was 370.2 females.

Female data: Lifetime records of mated gilts that entered herds in 2001 to 2003 were extracted from the data files of sows in the 101 herds. Of 38,591 females in the 101 herds, 379 gilts with an AFM $<187(\mathrm{~N}=249)$ or $>365$ days $(\mathrm{N}=130)$ were considered to be extreme [1], and these gilts 
were excluded. Hence, lifetime records in 38,212 gilts were used for further lifetime analyses. Of the 38,212 females, 575 were still active when the data were collected, and they were omitted when lifetime performance was analyzed. In addition, 70 records with a WMI $>120$ days were also considered to be extreme and were omitted [8] when these variables were used as dependent variables.

Definitions and categories of measurements: Females were categorized into the following five 21-day interval groups based around the median AFM of 240 days except for the last group: 188-208 days $(\mathrm{N}=1,621), 209-229$ days $(\mathrm{N}=9,449), 230-250$ days $(\mathrm{N}=12,993), 251-271$ days $(\mathrm{N}=7,874)$ and $272-365$ days $(\mathrm{N}=6,275)$. Herd productivity was measured as PWMFY. The overall mean PWMFY $( \pm$ SD) was $21.5 \pm 2.22$ pigs, ranging 16.4 to 25.1 pigs. Three herd groups were built on the basis of the upper and lower 25th percentiles of PWMFY: high- ( $>23.3$ pigs; 25 herds, $\mathrm{N}=12,352)$, intermediate- (20.0-23.3 pigs; 51 herds, $\mathrm{N}=18,464)$ and low-performing herds $(<20.0$ pigs; 25 herds, $\mathrm{N}=7,396)$. The following six parity groups were also built: $0(\mathrm{~N}=38,212), 1(\mathrm{~N}=35,297), 2(\mathrm{~N}=30,683), 3$ $(\mathrm{N}=27,617), 4(\mathrm{~N}=24,530)$ and $\geq 5(\mathrm{~N}=59,480)$. A gilt (parity 0 ) is defined as a female that has entered into a herd but has not farrowed, and a sow is defined as a female that has farrowed at least once.

Female life days was defined as the number of days from a female's date of birth to date of removal from the herd. Reproductive herd days was considered to be the period between the date of the first mating of gilts and their culling date. Lifetime nonproductive days (NPD) was the total number of days when females were neither gestating nor lactating in a herd [10]. Annualized lifetime PBA was defined as the total number of PBAs in a lifetime divided by the female life days multiplied by 365 days [12]. Lifetime total PBA, lifetime NPD and annualized lifetime PBA were calculated only for removed sows. Culling risk for each parity was calculated as the number of removed females divided by the number of surviving females at farrowing for the parity [3].

Statistical analysis: All statistical analyses were done with SAS (SAS Inst. Inc., Cary, NC, U.S.A). A chi-squared test was used to compare the relative frequency (\%) of AFM by the herd groups. A multilevel model was used to take into account the hierarchic structure of the individual females within a herd [14]. Two-level analysis was applied by using a herd at level 2 and an individual record at level 1 [14]. Continuous variables were analyzed by linear mixedeffects models using the MIXED procedure with TukeyKramer multiple comparisons. Binomial variables were analyzed with mixed-effects logistic regression models using the GLIMMIX procedure with contrasts. In addition, normality of the AFM was confirmed using rankit plots and the Wilk-Shapiro test in the Univariate procedure.

Model 1 was constructed to compare AFM between the three herd productivity groups. Model 2 was built to compare lifetime performance by the AFM groups. The dependent variable was parity at removal, reproductive herd days, female life days, lifetime NPD, lifetime total PBA or annualized lifetime PBA. Model 3 was constructed to compare reproductive measurements by parity groups between the AFM groups and the herd productivity groups. The dependent variable was culling risk, PBA, farrowing percentage or WMI. Independent variables in models 2 and 3 included the AFM groups, the herd groups and the interaction between the AFM and herd groups. Herd was included as a random intercept in order to adjust the variance component representing the effect of herd, and denominator degrees of freedom were estimated using the DDFM (denominator degree of freedom $=\mathrm{BW}$ (Between-Within) option. In addition, year of entry into the herd was also included as a random intercept.

\section{RESULTS}

The mean AFM ( \pm SEM) of all females in the 101 herds was $246.6 \pm 0.14$ days (range: $221.6-292.9$ days). The mean AFMs of the high-, intermediate- and low-performing herds were $239.5 \pm 0.22,247.4 \pm 0.21$ and $256.7 \pm 0.35$ days, respectively. The mean AFM of the high-performing herds was significantly higher than that of the low-performing herds $(P<0.05)$. Relative frequency $(\%)$ of AFM differed between the three herd groups $(P<0.05$; Table 1$)$. High-performing herds had more gilts mated at an earlier age, with $33.7 \%$ of gilts first mated at 209-229 days compared with only $22.7 \%$ and $14.7 \%$ in the intermediate- and low-performing herds, respectively.

Females with AFMs of 188-208 and 209-229 days had a higher annualized lifetime PBA, parity at removal and reproductive herd days than those with AFMs of 230-250, 251-271 and 272-365 days $(P<0.05$; Table 2$)$. No difference was found in lifetime NPD between the AFM groups. The annualized lifetime PBA, lifetime PBA and parity at removal of the females with an AFM of 209-229 days were similar to those of females with an AFM of 188-208 days. Additionally, females with an AFM of 272-365 days had the lowest annualized lifetime PBA, lifetime PBA and parity at removal and the shortest reproductive herd days of the AFM groups $(P<0.05)$. No interaction was found between the AFM and the herd productivity groups for lifetime performance.

Tables 3 and 4 show the comparisons of reproductive performance by parity groups between the AFM groups. There was no difference in culling risk in any parity between females with an AFM of 209-229 days and those with an AFM of 230-250 days. There was also no difference in farrowing percentage and WMI between AFM 209-365 days for parity 2 or later. Females with an AFM of 209-229 days had 0.1 pigs fewer PBA in parity 1 , but had a lower culling risk in parities 0,1 and 2 and a shorter $W M I$ in parity 1 than those with an AFM of 251-271 days $(P<0.05)$. Additionally, females with an AFM of 209-229 days had a lower culling risk in parities $0,1,2$ and 3 and a shorter WMI in all parity groups than those with an AFM of 272-365 days $(P<0.05)$. 
Table 1. Relative frequency (\%) of age of gilts at first mating in 38,212 females**

\begin{tabular}{lcccc}
\hline & & \multicolumn{3}{c}{ Herd groups* } \\
\cline { 3 - 5 } $\begin{array}{l}\text { Age of gilts at first } \\
\text { mating in days }\end{array}$ & All herds & $\begin{array}{c}\text { High- } \\
\text { performing herds }\end{array}$ & $\begin{array}{c}\text { Intermediate- } \\
\text { performing herds }\end{array}$ & $\begin{array}{c}\text { Low- } \\
\text { performing herds }\end{array}$ \\
\hline $\mathrm{N}$ & 38,212 & 12,352 & 18,464 & 7,396 \\
$188-208$ & 4.2 & 5.3 & 4.4 & 2.2 \\
$209-229$ & 24.7 & 33.7 & 22.7 & 14.7 \\
$230-250$ & 34.1 & 35.7 & 34.1 & 30.9 \\
$251-271$ & 20.6 & 15.4 & 21.7 & 26.5 \\
$272-365$ & 16.4 & 9.9 & 17.1 & 25.7 \\
\hline
\end{tabular}

* Three herd groups were formed on the basis of the upper and lower 25 th percentiles of pigs weaned per mated female per year: high-, intermediate- and low-performing herds.

** Relative frequencies differed significantly between the three performing herds $(P<0.05)$. Frequencies within a column add up to $100 \%$.

Table 2. Comparisons of lifetime performance between five groups based on the ages of the gilts at first mating

\begin{tabular}{|c|c|c|c|c|c|c|}
\hline \multirow[b]{2}{*}{ Measurements } & \multicolumn{6}{|c|}{ Ages of the gilts at first mating in days } \\
\hline & $188-208$ & $209-229$ & $230-250$ & $251-271$ & $272-365$ & RtR* \\
\hline $\mathrm{N}$ & 1,606 & 9,360 & 12,793 & 7,743 & 6,135 & \\
\hline Parity at removal & $4.9^{\mathrm{a})}$ & $4.8^{\mathrm{a})}$ & $4.7^{\mathrm{b})}$ & $4.5^{\mathrm{c})}$ & $4.1^{\mathrm{d})}$ & 2.65 \\
\hline Reproductive herd days & $768.6^{\mathrm{a})}$ & $745.6^{\mathrm{a})}$ & $729.1^{\mathrm{b})}$ & $718.0^{\mathrm{c})}$ & $668.3^{\mathrm{d})}$ & 370.65 \\
\hline Female life days & $971.0^{\mathrm{ab})}$ & $966.3^{\mathrm{ab})}$ & $968.8^{\mathrm{a})}$ & $977.7^{\mathrm{a})}$ & $963.5^{\mathrm{b})}$ & 370.49 \\
\hline Lifetime nonproductive days & 92.2 & 93.0 & 92.9 & 96.6 & 100.9 & 71.29 \\
\hline $\mathrm{N}^{* *}$ & 1,520 & 8,731 & 11,871 & 7,125 & 5,476 & \\
\hline Lifetime total pigs born alive & $54.8^{\mathrm{a})}$ & $54.5^{\mathrm{a})}$ & $52.9^{\mathrm{ab})}$ & $51.5^{\mathrm{b})}$ & $48.1^{\mathrm{c})}$ & 128.23 \\
\hline Annualized lifetime pigs born alive & $18.5^{\mathrm{a})}$ & $18.2^{\mathrm{a})}$ & $17.5^{\mathrm{b})}$ & $16.6^{\mathrm{c})}$ & $15.3^{\mathrm{d})}$ & 5.86 \\
\hline
\end{tabular}

a-d) Means (within a row) followed by different letters differ $(P<0.05)$.

* RtR $=$ the root residual of the covariance parameter estimate in the mixed model. Pooled SEM can be estimated by the root residual divided by root $n$.

** Lifetime total pigs born alive and annualized lifetime pigs born alive were the available for only sows.

\section{DISCUSSION}

The present study showed that high-performing herds had an approximately two-week earlier AFM and had 19\% higher proportions of females with an AFM of 209-229 days than low-performing herds. These results indicate that high-performing herds are managed in a way that enables gilt development at a lower AFM than for low-performing herds. AFM may be affected by an intrinsic nature of the age at puberty in the gilt and the herd management for gilt development [2]. Producers can manipulate the time at which puberty is reached to some extent by using contact with a mature boar and an adequate growth rate during the rearing period.

Our study shows a large variation for the AFM for the females in all herd groups. This variation may be due to biological variation in the age at which gilts reach puberty [11] and the management practices of the producers in order to ensure a consistent flow of mated females each week [4]. In the commercial herds, matured gilts are used to adjust the number of mated females per mating group [6] because the consistent flow of pig production through a facility is commonly given priority.

Our study showed that females with a lower AFM, i. e., 229 days or lower, had higher longevity and higher lifetime efficiency than those with a higher AFM in all the herd groups. This finding is consistent with a previous study showing a relationship between decreased ages of gilts at first farrowing and increased number of parities at culling and productivity per sow per year [8]. In the present study, the lower culling risk until parity 3 , and the higher parity at removal in females with a low AFM than those with a high AFM, indicates that decreasing AFM does not necessarily increase culling risk or decrease longevity in females. It is noteworthy that excessive weight gain of gilts during a breeding period, which is used to decrease AFM, might negatively affect the physical fitness of gilts and thereby decrease sow longevity [2].

This is the first report showing that differences in AFM between 209-271 days had little or no effect on farrowing percentage or WMI in mid or high parity groups. Our study indicates that AFM has less of an effect on PBA in mid or high parity than in low parity, and this is consistent with previous studies showing that females with a high AFM have more PBAs in parity 1 and 2 than those with a low AFM [1, $13,17]$. In conclusion, we recommend management practices that increase the proportion of gilts having a lower AFM within a herd.

Finally, the present study was an observational study using records from commercial herds. Our results could be 
Table 3. Comparisons of reproductive performance between five groups based on the ages of the gilts at first mating by parity groups

\begin{tabular}{lrrrrrr}
\hline Age of gilts at first & \multicolumn{7}{c}{ Parity } \\
\cline { 2 - 7 } mating in days & \multicolumn{1}{c}{1} & 2 & 3 & 4 & $\geq 5^{2)}$ \\
\hline Number of surviving females $^{1)}$ & & & & & & \\
$188-208$ & 1,621 & 1,535 & 1,367 & 1,259 & 1,130 & 2,760 \\
$209-229$ & 9,449 & 8,820 & 7,818 & 7,135 & 6,397 & 15,301 \\
$230-250$ & 12,993 & 12,071 & 10,524 & 9,511 & 8,496 & 20,595 \\
$251-271$ & 7,874 & 7,255 & 6,247 & 5,595 & 4,941 & 12,159 \\
$272-365$ & 6,275 & 5,616 & 4,727 & 4,117 & 3,566 & 8,665 \\
Culling risk, \%* & & & & & & \\
$188-208$ & $5.3^{\mathrm{y})}$ & $10.6^{\mathrm{yz})}$ & $7.9^{\mathrm{y})}$ & $10.4^{\mathrm{wx})}$ & 11.8 & 18.5 \\
$209-229$ & $6.7^{\mathrm{y})}$ & $11.1^{\mathrm{z})}$ & $8.7^{\mathrm{y})}$ & $10.4^{\mathrm{x})}$ & 12.8 & 16.7 \\
$230-250$ & $7.1^{\mathrm{y})}$ & $12.6^{\mathrm{xy})}$ & $9.7^{\mathrm{xy})}$ & $10.7^{\mathrm{x})}$ & 14.0 & 16.8 \\
$251-271$ & $7.8^{\mathrm{x})}$ & $13.6^{\mathrm{x})}$ & $10.5^{\mathrm{x})}$ & $11.7^{\mathrm{x})}$ & 13.1 & 18.6 \\
$272-365$ & $10.5^{\mathrm{w})}$ & $16.4^{\mathrm{w})}$ & $12.9^{\mathrm{w})}$ & $13.5^{\mathrm{w})}$ & 14.4 & 19.1 \\
RtR** & 2.63 & 3.33 & 2.98 & 3.14 & 3.40 & 3.76 \\
Number of pigs born alive & & & & & & \\
$188-208$ & - & $9.5^{\mathrm{x})}$ & $10.2^{\mathrm{wx})}$ & 10.8 & 11.1 & $10.8^{\mathrm{wx})}$ \\
$209-229$ & - & $9.6^{\mathrm{x})}$ & $10.3^{\mathrm{x})}$ & 11.1 & 11.2 & $10.8^{\mathrm{wx})}$ \\
$230-250$ & - & $9.8^{\mathrm{w})}$ & $10.3^{\mathrm{x})}$ & 10.9 & 11.1 & $10.7^{\mathrm{w})}$ \\
$251-271$ & - & $9.7^{\mathrm{w})}$ & $10.4^{\mathrm{w})}$ & 10.8 & 11.0 & $10.5^{\mathrm{wx})}$ \\
$272-365$ & - & $9.8^{\mathrm{w})}$ & $10.4 \mathrm{w}^{\mathrm{x})}$ & 10.9 & 10.8 & $10.3^{\mathrm{x})}$ \\
RtR & - & 2.99 & 3.03 & 3.07 & 3.07 & 3.13 \\
\hline
\end{tabular}

w-z) Means (within a column) followed by different letters differ $(P<0.05)$.

1) 575 females that were still active when the data were collected.

2) Of 59,480 females, the proportions of females in parities 5, 6, 7, 8, 9 and 10 or more were 35.3, 29.2, $20.8,10.0,3.6$ and $1.1 \%$, respectively.

* In parity $\geq 5$, culling risk was calculated as culling risk in parity 5 . The numbers of sows with ages at first mating of 188-208, 209-229, 230-250, 251-271 and 272-365 days were 997, 5,581, 7,300, 4,295 and 3,053 pigs, respectively.

** $\mathrm{RtR}=$ the root residual of the covariance parameter estimate in the mixed model. Pooled SEM can be estimated by the root residual divided by root $n$.

Table 4. Comparisons of reproductive performance between five groups based on the ages of the gilts at first mating by parity groups

\begin{tabular}{|c|c|c|c|c|c|c|}
\hline \multirow{2}{*}{$\begin{array}{l}\text { Age of gilts at first } \\
\text { mating in days }\end{array}$} & \multicolumn{6}{|c|}{ Parity } \\
\hline & 0 & 1 & 2 & 3 & 4 & $\geq 5^{1)}$ \\
\hline \multicolumn{7}{|c|}{ Numbers of serviced females } \\
\hline 188-208 & 1,621 & 1,445 & 1,323 & 1,210 & 1,066 & 1,988 \\
\hline 209-229 & 9,449 & 8,294 & 7,568 & 6,802 & 6,039 & 10,980 \\
\hline $230-250$ & 12,993 & 11,216 & 10,056 & 9,021 & 7,919 & 15,076 \\
\hline $251-271$ & 7,874 & 6,659 & 5,940 & 5,270 & 4,633 & 8,941 \\
\hline $272-365$ & 6,275 & 5,115 & 4,421 & 3,823 & 3,317 & 6,337 \\
\hline \multicolumn{7}{|c|}{ Farrowing percentage, $\%$} \\
\hline $188-208$ & $84.4^{\mathrm{x})}$ & $83.9^{\mathrm{xy})}$ & 88.1 & 86.3 & $88.7^{\mathrm{x})}$ & 84.5 \\
\hline $209-229$ & $82.5^{\mathrm{x})}$ & $84.1^{\mathrm{xy})}$ & 87.0 & 87.4 & $86.2^{\mathrm{y})}$ & 84.4 \\
\hline $230-250$ & $82.0^{\mathrm{x})}$ & $84.4^{\mathrm{x})}$ & 86.8 & 86.7 & $85.3^{\mathrm{y})}$ & 83.0 \\
\hline $251-271$ & $81.0^{\mathrm{x})}$ & $83.6 \mathrm{x}^{\mathrm{y})}$ & 86.0 & 85.9 & $85.3^{\mathrm{y})}$ & 82.1 \\
\hline $272-365$ & $77.9^{\mathrm{y})}$ & $82.0^{\mathrm{y})}$ & 84.7 & 86.0 & $83.9^{\mathrm{y})}$ & 81.8 \\
\hline $\mathrm{RtR}^{*}$ & 3.85 & 3.65 & 3.40 & 3.39 & 3.49 & 3.71 \\
\hline \multicolumn{7}{|c|}{ Weaning-to-first mating interval, day } \\
\hline $188-208$ & - & $7.9^{\mathrm{y})}$ & $6.2^{\mathrm{xy})}$ & $6.1^{\mathrm{xy})}$ & $5.9^{\mathrm{xy})}$ & $5.7^{\mathrm{xy})}$ \\
\hline 209-229 & - & $8.6^{\mathrm{y})}$ & $6.7^{\mathrm{y})}$ & $6.1^{\mathrm{y})}$ & $6.0^{\mathrm{y})}$ & $5.7^{\mathrm{y})}$ \\
\hline $230-250$ & - & $9.0^{\mathrm{y})}$ & $6.8^{\mathrm{y})}$ & $6.4^{\mathrm{y})}$ & $6.2^{\mathrm{y})}$ & $5.9^{\mathrm{y})}$ \\
\hline $251-271$ & - & $9.8^{\mathrm{x})}$ & $7.1^{\mathrm{xy})}$ & $6.8^{\mathrm{xy})}$ & $6.3^{\mathrm{y})}$ & $6.0^{\mathrm{y})}$ \\
\hline $272-365$ & - & $10.1^{\mathrm{x})}$ & $7.5^{\mathrm{x})}$ & $7.0^{\mathrm{x})}$ & $6.7^{\mathrm{x})}$ & $6.1^{\mathrm{x})}$ \\
\hline $\mathrm{RtR}^{*}$ & - & 10.82 & 7.24 & 6.39 & 5.51 & 4.97 \\
\hline
\end{tabular}

$\mathrm{x}$-y) Means (within a column) followed by different letters differ $(P<0.05)$.

1) Of 43,322 females, the proportions of females in parities $5,6,7,8,9$ and 10 or more were $44.0,32.0,15.9,6.1,1.5$ and $0.5 \%$, respectively.

$* \mathrm{RtR}=$ the root residual of the covariance parameter estimate in the mixed model. Pooled SEM can be estimated by the root residual divided by root $\mathrm{n}$. 
biased by herd health, genetics, growth rates of gilts, weights at first mating in gilts and culling policy, which we did not measure. Even with such limitations, the present study provides valuable information on AFM for swine producers and veterinarians to apply to their practices and production.

ACKNOWLEDGMENTS. The authors gratefully thank the cooperating swine producers for providing their valuable data and the PigCHAMP staff at Global Pig Farms, Inc. (Shibukawa, Gunma, Japan) for technical assistance. We also thank Dr. I. McTaggart for critical review of this manuscript. This research was supported by Research Project Grants from Meiji University and the High-Tech Research Center of the Ministry of Education, Culture, Sports, Science and Technology of Japan.

\section{REFERENCES}

1. Babot, D., Chavez, E. R. and Noguera, J. L. 2003. The effect of age at the first mating and herd size on the lifetime productivity of sows. Anim. Res. 52: 49-64.

2. Foxcroft, G. and Aherne, F. 2001. Rethinking management of the replacement gilt. Adv. Pork. Product. 12: 197-210.

3. Friis, R. H. and Sellers, T. A. 1996. Epidemiology for Public Health Practice. Aspen Publishers, Gaithersburg, MD, U.S.A.

4. Koketsu, Y. 2005. Within-farm variability in age structure of breeding-female pigs and reproductive performance on commercial swine breeding farms. Theriogenology 63: 1256-1265.

5. Koketsu, Y. 2007. Longevity and efficiency associated with age structures of female pigs and herd management in commercial breeding herds. J. Anim. Sci. 85: 1086-1091.

6. Koketsu, Y., Duangkaew, C., Dial, G. D. and Reeves, D. E. 1999. Within-farm variability in number of females mated per week during a one-year period and breeding herd productivity on swine farms. J. Am. Vet. Med. Assoc. 214: 520-524.

7. Koketsu, Y., Takahashi, H. and Akachi, K. 1999. Longevity, lifetime pig production and productivity, and age at first conception in a cohort of gilts observed over six years on commercial farms. J. Vet. Med. Sci. 61: 1001-1005.

8. Le Cozler, Y., Dagorn. J., Lindberg, J. E., Aumaitre, A. and Dourmad, J. Y. 1998. Effect of age at first farrowing and herd management on long-term productivity of sows. Livest. Prod. Sci. 53: 135-142.

9. MAFF statistics. Ministry of Agriculture, Forestry and Fishery Statistics in Japan. Available at www.maff.go.jp/index.html (Accessed on 15 August 2007).

10. PigCHAMP. 1996. PigCHAMP Reports Manual. University of Minnesota, St. Paul.

11. Rozeboom, D. W., Pettigrew, J. E., Moser, R. L., Cornelius, S. G. and El Kandelgy, S. M. 1995. Body composition of gilts at puberty. J. Anim. Sci. 73: 2524-2531.

12. Sasaki, Y. and Koketsu, Y. 2008. Sows having high lifetime efficiency and high longevity associated with herd productivity in commercial herds. Livest. Sci. 118: 140-146.

13. Schukken, Y. H., Buurman, J., Huirne, R. B. M., Willemse, A. H., Vernooy, J. C. M., van den Broek, J. and Verheijden, J. H. M. 1994. Evaluation of optimal age at first conception in gilts from data collected in commercial swine herds. J. Anim. Sci. 72: 1387-1392.

14. Singer, J. D. 1998. Using SAS PROC MIXED to fit multilevel models, hierarchical models, and individual growth models. $J$. Educ. Behav. Stat. 23: 323-355.

15. Stein, T. E., Duffy, S. J. and Wickstrom, S. 1990. Difference in production values between high- and low-productivity swine breeding herds. J. Anim. Sci. 68: 3972-3979.

16. Sterning, M., Rydhmer, L. and Eliasson-Selling, L. 1998. Relationships between age at puberty and interval from weaning to estrus and between estrus signs at puberty and after the first weaning in pigs. J. Anim. Sci. 76: 353-359.

17. Tummaruk, P., Lundeheim, N., Einarsson, S. and Dalin, A.-M. 2001. Repeat breeding and subsequent reproductive performance in Swedish Landrace and Swedish Yorkshire sows. Anim. Reprod. Sci. 67: 267-280. 